
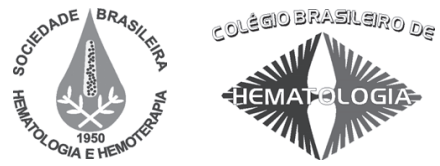

\title{
Controle genético das células-tronco humanas cultivadas
}

\section{Genetic control of cultivated human stem cells}

Spencer L. M. Payãol

Rosimeire Segato ${ }^{2}$

Ricardo R. Santos ${ }^{3}$

\begin{abstract}
As células-tronco apresentam uma alta capacidade de autorregeneração, assim como, um potencial de diferenciação em uma variedade de tipos celulares. Estas células podem ser classificadas como embrionárias e adultas. Apesar de apresentar propriedades de células-tronco, as mesenquimais apresentam um certo grau de dificuldade no estabelecimento das culturas, podendo induzir a perda da expressão da enzima responsável pela imortalização ou enzima telomerase. A enzima telomerase é considerada um relógio biológico, um indicador que a senescência celular irá se instalar inevitavelmente. A questão mais atual e intrigante dos pesquisadores é se o suposto potencial de divisão, por um determinado período de tempo, das células-tronco cultivadas poderia levar ao acúmulo de alterações genéticas e epigenéticas, resultando em um processo neoplásico. Dai a importância do papel da citogenética humana no controle e monitoramento das células-tronco cultivadas que serão utilizadas na terapia em seres humanos. Alterações cromossômicas estruturais, tais como deleções, translocações e inversões, representam um mecanismo importante pelo qual as células cancerígenas desenvolvem-se gradualmente, uma vez que estas alterações cromossômicas podem levar a uma expressão anormal de muitos genes, podendo desencadear assim o processo neoplásico. Rev. Bras. Hematol. Hemoter. 2009;31(Supl. 1):15-18.
\end{abstract}

Palavras-chave: Células-tronco cultivadas; controle citogenético; bandamento G; SKY (cariótipo espectral).

\section{Introdução}

As células-tronco apresentam uma alta capacidade de autorregeneração, assim como um potencial de diferenciação em uma variedade de tipos celulares. Estas células podem ser classificadas como embrionárias e adultas. As células-tronco embrionárias derivam-se do blastocisto e possuem a capacidade de se diferenciarem em todos os tecidos humanos. Um exemplo de células-tronco adultas são as células mesenquimais, as quais estão presentes em uma variedade de tecidos, como medula óssea, tecido adiposo, sangue de cordão umbilical e têm a capacidade de se diferenciarem em ossos, cartilagem, tecido adiposo e musculares, dentre outros. ${ }^{1,2}$ Apesar de apresentarem propriedades de células-tronco, as mesenquimais apresentam um certo grau de dificuldade no estabelecimento das culturas, podendo perder a expressão da enzima responsável pela imortalização ou enzima telomerase. Vários estudos mostram que os telômeros encurtam-se com o envelhecimento em células humanas somáticas normais e mantêm seu tamanho estável em células tumorais. ${ }^{3-6}$

A regulação do tempo de vida das células humanas in vitro se dá por dois aspectos: a senescência/apoptose e a

${ }^{1}$ Diretor de Pós-graduação, Pesquisa e Extensão da Faculdade de Medicina de Marília (Famema) - SP. Pesquisador da Pós-graduação em Biologia Oral da USC - Bauru-SP.

${ }^{2}$ Bióloga. Assistente técnica $V$ do Laboratório de Genética da Famema - Marília - SP.

${ }^{3}$ Professor Titular. Coordenador do Instituto de Bioengenharia Tecidual da Fiocruz de Salvador - BA.

Faculdade de Medicina de Marilia (Famema), SP, e Fiocruz de Salvador, BA.

Correspondência: Spencer Luiz Marques Payão

Laboratório de Genética, Hemocentro, Famema

Rua Lourival Freire, 240 - Bairro Fragata

17519-050 - Marília-SP - Brasil

Tel.: (55 14) 3402-1856 - Fax: (55 14) 3433-0148

E-mail:slmpayao@famema.br

Doi: 10.1590/S1516-84842009005000021 
fase de crise e transformação neoplásica. A senescência está associada ao encurtamento dos telômeros e ao bloqueio do ciclo celular. ${ }^{7}$ Se as células passarem deste estágio, elas continuarão a crescer até que o encurtamento dos telômeros se torne crítico. A partir daí, as células entrariam em crise caracterizada pela instabilidade cromossômica generalizada, que provoca uma apoptose em massa. ${ }^{8}$ A questão mais atual e intrigante dos pesquisadores é se o suposto potencial de divisão, por um determinado período de tempo, das células-tronco cultivadas poderia levar ao acúmulo de alterações genéticas e epigenéticas, resultando em um processo neoplásico. Daí a importância do papel da citogenética humana no controle e monitoramento das células-tronco cultivadas, que serão utilizadas na terapia em seres humanos. ${ }^{9}$ Alterações cromossômicas estruturais, tais como deleções, translocações e inversões, representam um mecanismo importante pelo qual as células cancerígenas desenvolvem-se gradualmente, uma vez que estas alterações cromossômicas podem levar a uma expressão anormal de muitos genes, podendo desencadear assim o processo neoplásico. ${ }^{10}$ Situação similar tem sido observada em células-tronco embrionárias humanas cultivadas. Embora alterações em um grande número de genes pareçam raras nas células-tronco embrionárias cultivadas, linhagens destas células-tronco, derivadas independentemente em diferentes laboratórios do mundo, têm evidenciado as mesmas alterações cromossômicas recorrentes, das quais as mais frequentes são as trissomias dos cromossomos 12 e 17..$^{11,12}$ A poliploidia representa um estágio no qual as células possuem mais do que dois conjuntos cromossômicos, e estas células poliploides podem se originar após o estresse celular, envelhecimento e em várias doenças, talvez devido à poliploidia representar um benefício metabólico. ${ }^{13,14}$ Por outro lado, a poliploidia também tem suas desvantagens, uma vez que evidências sugerem que as células poliploides são geneticamente instáveis e podem agir como um passo intermediário para a tumorigênese. Esta hipótese pode explicar por que muitos tipos de câncer contêm consideráveis alterações no número dos cromossomos e raramente apresentam ganho ou perda de um único cromossomo. ${ }^{15} \mathrm{~A}$ técnica de FISH (Fluorescence in situ hybridization) tem aumentado consideravelmente a possibilidade dos laboratórios de citogenética clínica detectarem alterações menores do genoma humano. Utilizando sondas lócus e genes específicos, hibridadas com materiais humanos de pacientes, os resultados podem ser obtidos de uma forma simples e bastante segura. A grande limitação atual da citogenética clássica por meio da análise em bandamento $\mathrm{G}$ é a presença de cromossomos não identificáveis, denominados "cromossomos marcadores", ou seja, cuja origem é desconhecida. Uma alternativa seria a utilização da técnica de CGH (Comparative genomic hybridization).${ }^{16} \mathrm{~A}$ técnica de CGH é trabalhosa e custosa e não possui uma resolução e sensibilidade adequadas para detectar aberrações cromossômicas desbalanceadas menores. Uma tecnologia mais recente da citogenética molecular tem permitido investigar o genoma inteiro através de um único experimento de FISH, elucidando a presença de rearranjos cromossômicos, particularmente translocações, inserções, adições e outras alterações estruturais mais complexas que resultam em cromossomos marcadores. Este método, genericamente denominado de SKY (Spectral karyotyping), ${ }^{17}$ tem a possibilidade de gerar combinações resultantes em 24 cores diferentes, identificando através de pintura cada par cromossômico em um único experimento. Além disso, é possível, através desta técnica, elucidar uma aberração estrutural latente que não poderia ser detectada pela citogenética clássica. Fan et al. ${ }^{18}$ descreveram que o menor limite para detecção de um segmento cromossômico é de pelo menos 1-2MB (megabases). Sendo assim, a origem cromossômica de todos os marcadores pode ser identificada com segurança. Devido ao referido acima, a técnica clássica de identificação dos cromossomos em bandamento $\mathrm{G}$, considerada padrão ouro na análise citogenética, e a técnica de SKY estão sendo propostas no presente projeto.

A medicina regenerativa e a terapia celular representam enfoques emergentes no conhecimento da biologia das células-tronco. Se o papel das células-tronco na manutenção da homeostase tecidual está claro, sua participação para o desenvolvimento do câncer ainda requer bastante investigação, e a presente proposta ressalta, como foco principal, a pesquisa nesta área do conhecimento. Portanto, para um tumor crescer, tornar-se metastático e sofrer recorrência após intervenção terapêutica, a presença de subpopulações de células com grande capacidade de autorrenovação, assim como as células-tronco, representaria um direcionamento biológico comum. A hipótese das células-tronco promoverem o desenvolvimento do câncer se baseia no fato destas células serem particularmente alvos suscetíveis de carcinogênese e, consequentemente, dar origem a diferentes tipos de câncer. A utilização das células-tronco humanas cultivadas em laboratório necessita da garantia de um controle exaustivo e rigoroso com respeito à qualidade, confiabilidade e rastreabilidade. A instabilidade genética, caracterizada pelas anormalidades cromossômicas, representa uma importante lacuna em estudos básicos visando aplicações terapêuticas, utilizando linhagens de células-tronco cultivadas. Sendo assim, o monitoramento citogenético da transformação tumoral representa o aspecto mais importante do presente projeto. Considerada uma abordagem recente, a possibilidade de expandir em cultura o número de células-tronco mesenquimais, assim como a utilização de células-tronco embrionárias cultivadas visando tratar um número maior de patologias, a caracterização citogenética destas células seria de fundamental importância para um futuro recente. ${ }^{9}$ Desta forma, o estabelecimento de um programa citogenético na determinação da instabilidade cromossômica/transformação neoplásica é um ponto crucial no estabelecimento das linhagens de células-tronco cultiva- 
das em laboratório e abordagem fundamental e inédita no Brasil. Os três centros colaboradores e fornecedores das linhagens de células-tronco cultivadas - Fiocruz de Salvador, PUC de Curitiba e Universidade Federal do Rio de Janeiro (UFRJ) - estão entre os mais atuantes no Brasil no desenvolvimento de protocolos de pesquisa com seres humanos. O principal intuito do monitoramento da transformação tumoral em cultura é evitar a transferência de células com potencial de transformação neoplásica para o tratamento de diferentes patologias, estando os pacientes suscetíveis ao desenvolvimento de tumores, principalmente se estiverem imunodeprimidos no momento do transplante destas células. É importante ainda ressaltar que o desenvolvimento de um controle de qualidade e rastreabilidade genético das células-tronco cultivadas está totalmente de acordo com as normas preconizadas pela Anvisa na categoria "Centro de Terapia Celular Tipo 3 (CTC3)", ou seja, serviço que realiza atividades com células-tronco humanas adultas e/ou embrionárias, criopreservadas ou não, autólogas ou alogênicas, para uso em pesquisa clínica e/ou uso terapêutico, que mantém células em cultura.

A presente proposta envolvendo o controle e monitoramento de proliferação/transformação tumoral de células-tronco adultas mesenquimais cultivadas (tecido adiposo, medula óssea, decíduas de dente de leite humano e de dente de indivíduos adultos) e embrionárias cultivadas tem como objetivos:

- Caracterizar e monitorar citogeneticamente, por bandamento $\mathrm{G}$, as passagens sequenciais destas células-tronco cultivadas;

- Elucidar por meio da técnica de SKY, rearranjos menores da ordem de $1 \mathrm{MB}$ envolvendo possíveis cromossomos marcadores, não identificáveis por bandamento G.

Metas a serem alcançadas: por meio da caracterização citogenética e citogenética molecular será possível determinar os mecanismos de alterações genéticas que podem resultar em transformação neoplásica das células-tronco cultivadas, visando o uso destas células, com segurança, em protocolos clínicos experimentais através de transplante em pacientes com diferentes patologias, tais como: cardiopatias, hepatopatias, entre outras. Além da análise em bandamento G, para todas as linhagens de células-tronco cultivadas, e da técnica de SKY, para a elucidação de alterações cromossômicas não detectáveis por bandamento $\mathrm{G}$, será utilizada a técnica de FISH com sondas comerciais para diferentes marcadores tumorais.

\section{Metodologia}

Todas as células deverão ser cultivadas e congeladas da primeira até a vigésima passagens e analisadas quanto ao grau e capacidade de confluência, paralelamente ao monitoramento citogenético, segundo descrição que se segue:
Inicialmente, todas as células obtidas da primeira, décima e vigésima passagens deverão ser analisadas em bandamento G. A segunda etapa de análise seria dependente da detecção e rastreamento de alterações cromossômicas estruturais e/ou numéricas em passagens específicas das culturas, exemplificando: se determinada cultura evidenciar a presença de metáfases alteradas na vigésima e não na décima passagem, todas as culturas a partir da décima primeira serão investigadas quanto à frequência de alterações cromossômicas. Todas as metáfases obtidas de passagens específicas de culturas apresentando cromossomos marcadores serão submetidas à técnica de SKY (painting humano) visando a identificação deste(s) cromossomo(s) e associando-os com o processo pré ou neoplásico.

A proposta do presente artigo se concentra no estabelecimento de um programa de caracterização citogenética de células-tronco mesenquimais cultivadas e tem como objetivos/metodologia:

- Caracterizar e monitorar citogeneticamente, por bandamento $\mathrm{G}$, as passagens sequenciais destas células-tronco cultivadas;

- Elucidar, por meio da técnica de SKY, rearranjos menores da ordem de $1 \mathrm{MB}$ envolvendo possíveis cromossomos marcadores, não identificáveis por bandamento G.

\section{Bandamento G}

A análise em bandamento G é utilizada para detectar possíveis alterações numéricas e/ou estruturais nos cromossomos obtidos das diferentes passagens de culturas de células-tronco mesenquimais. Para o bandamento G, o material é gotejado em lâminas e envelhecido a $90^{\circ} \mathrm{C}$ por uma hora. Após, as lâminas são tratadas com tampão fosfato $0,06 \mathrm{M}$ (Merck) a $37^{\circ} \mathrm{C}$ e lavadas em água corrente. A coloração é realizada com corante Wright (Merck) diluído em tampão fosfato $0,06 \mathrm{M}$ (1:3). Por fim, as lâminas são lavadas novamente em água corrente e secas a temperatura ambiente. ${ }^{19}$ Sob aumento de $1.000 \mathrm{X}$, pelo menos vinte metáfases de cada amostra são contadas/analisadas quanto à presença de alterações numéricas e/ou estruturais, segundo classificação citogenética internacional, ${ }^{20} \mathrm{e}$ as imagens capturadas através dos softwares Band View e Image Pro Plus.

\section{SKY (Spectral karyotyping)}

A técnica de Spectral karyotyping (SKY) permite caracterizar qualitativa e quantitativamente perdas ou ganhos de material cromossômico de alta resolução, da ordem de $1 \mathrm{MB}$ com considerável sensibilidade e especificidade. O presente protocolo utilizará sondas SKY Paint e consistirá de cinco etapas: a) preparação das lâminas através de gotejamento do material das culturas; $b$ ) pré-tratamento das lâminas e desnaturação da sonda; c) hibridação da lâmina durante 53 horas a $37^{\circ} \mathrm{C}$; d) detecção das sondas 
de SKY com duração de aproximadamente cinco horas; e e) análise e aquisição das imagens imediatamente após as etapas de detecção. ${ }^{17}$

\section{Principais contribuições científicas e tecnológicas}

Visando desenvolver, com eficácia, o monitoramento citogenético das células-tronco adultas e embrionárias cultivadas, por meio da utilização das mais atuais e sensíveis técnicas citogenéticas disponíveis nos principais centros de excelência do mundo, a aplicação destas certamente trará como contribuições científicas e aplicadas:

1) O melhor entendimento da Biologia do comportamento das células-tronco adultas e embrionárias cultivadas;

2) O monitoramento citogenético de alta definição através da técnica de SKY permitirá a elucidação dos diferentes marcadores neoplásicos nos momentos da diferenciação das células e o aspecto mais importante;

3) Considerando que o uso de células-tronco humanas cultivadas em laboratório necessita da garantia de um controle exaustivo e rigoroso com respeito à qualidade, confiabilidade e rastreabilidade, a presente proposta do estabelecimento de um programa de controle citogenético na determinação da instabilidade cromossômica e do processo neoplásico, é um ponto crucial para utilização destas células com segurança em diversas patologias.

\section{Abstract \\ Stem cells have a high capacity of self-regeneration, as well as a potential to differentiate into several cell types. These cells can be classified as embryonic or adult. In spite of having inherent properties of stem cells, mesenchymal cells show a certain degree of difficulty to establish cultures. This might induce a loss of the expression of the telomerase enzyme which is considered to be a biological clock or an indicator of the senescence of the cells. The most current and intriguing question for researchers is whether the presumed division potential of cultivated stem cells, over a period of time could result in an accumulation of genetic alterations and consequently, in a neoplastic process. For this reason, cytogenetic techniques are very important to guarantee the control and safety of cultivated stem cells to be used in human therapy. Structural chromosomal alterations, such as for example, deletions, translocations and inversions represent an important mechanism by which cells might gradually transform in a neoplastic process. Thus, these chromosomal alterations could result in an abnormal expression of the genes and lead to cancer. Rev. Bras. Hematol. Hemoter. 2009;31(Supl. 1):15-18.}

Key words: Cultivated stem cells; cytogenetic control; G-banding; SKY (spectral karyotyping).

\section{Referências Bibliográficas}

1. Pardal R, Clarke MF, Morrison SJ. Applying the principles of stem-cell biology to cancer. Nat Rev Cancer. 2003;3(12):895902.

2. Czyz J, Wiese C, Rolletschek A, Blyszczuk P, Cross M, Wobus AM. Potential of embryonic and adult stem cells in vitro. Biol Chem. 2003;384(10-11):1391-409.

3. van Steensel B, Smogorzewska A, de Lange T. TRF2 protects human telomeres from end-to-end fusions. Cell. 1998;92(3):401-13.

4. Masutomi K, Hahn WC. Telomerase expression - only half the story. Cancer Biol Ther. 2003;2(6):685-6.

5. Sharpless NE, DePinho RA. Telomeres, stem cells, senescence, and cancer. J Clin Invest. 2004;113(2):160-8.

6. Gimble JM, Katz AJ, Bunnell BA. Adipose-derived stem cells for regenerative medicine. Circ Res. 2007;100(9):1249-60.

7. Lloyd AC. Limits to lifespan. Nat Cell Biol. 2002;4(2):E25-7.

8. Rubio D, Garcia-Castro J, Martín MC, de la Fuente R, Cigudosa JC, Lloyd AC, et al. Spontaneous human adult stem cell transformation. Cancer Res. 2005;65(8):3035-9.

9. Catalina P, Cobo F, Cortés JL, Nieto AI, Cabrera C, Montes R, et al. Conventional and molecular cytogenetic diagnostic methods in stem cell research: a concise review. Cell Biol Int. 2007; 31(9):861-9.

10. Duesberg P, Li R, Fabarius A, Hehlmann R. The chromosomal basis of cancer. Cell Oncol. 2005;27(5-6):293-318.

11. Hoffman LM, Carpenter MK. Human embryonic stem cell stability. Stem Cell Rev. 2005;1(2):139-44.

12. Meisner LF, Johnson JA. Protocols for cytogenetic studies of human embryonic stem cells. Methods. 2008;45(2):133-41.

13. Storchova Z, Pellman D. From polyploidy to aneuploidy, genome instability and cancer. Nat Rev Mol Cell Biol. 2004;5(1):45-54.

14. Comai L. The advantages and disadvantages of being polyploid. Nat Rev Genet. 2005;6(11):836-46.

15. Ganem NJ, Storchova Z, Pellman D. Tetraploidy, aneuploidy and cancer. Curr Opin Genet Dev. 2007;17(2):157-62.

16. Kallioniemi OP, Kallioniemi A, Piper J, Isola J, Waldman FM, Gray JW, et al. Optimizing comparative genomic hybridization for analysis of DNA sequence copy number changes in solid tumors. Genes Chromosomes Cancer. 1994;10(4):231-43.

17. Bayani J, Squire JA. Advances in the detection of chromosomal aberrations using spectral karyotyping. Clin Genet. 2001;59(2):65-73.

18.-Fan YS, Siu VM, Jung JH, Xu J. Sensitivity of multiple color spectral karyotyping in detecting small interchromosomal rearrangements. Genet. Genet Test. 2000;4(1):9-14.

19. Sanchez O, Escobar JI, Yunis JJ. A simple G-banding technique. Lancet. 1973;2(7823):269.

20. ISCN: An International System for Human Cytogenetic Nomenclature. Mitelman F. ed. Karger, Basel, 2005, P 130.

Avaliação: O tema apresentado consta da pauta elaborada pelo editor, Professor Milton Artur Ruiz, e coeditores deste suplemento, Professores Sergio Paulo Bydlowski e Adriana Seber.

Conflito de interesse: não declarado

Recebido: $22 / 10 / 2008$

Aceito: $23 / 10 / 2008$ 